\title{
Article \\ Biofunctional Hyaluronic Acid/к-Carrageenan Injectable Hydrogels for Improved Drug Delivery and Wound Healing
}

\author{
Uzma Ijaz ${ }^{1}$, Muhammad Sohail 1,*(D), Muhammad Usman Minhas ${ }^{2}$, Shahzeb Khan ${ }^{3,4}$ (D), Zahid Hussain $^{5,6}$, \\ Mohsin Kazi ${ }^{7}$ (D), Syed Ahmed Shah ${ }^{1,8}$, Arshad Mahmood ${ }^{9}$ and Mohammed Maniruzzaman ${ }^{10}$ (D)
}

check for updates

Citation: Ijaz, U.; Sohail, M.; Usman Minhas, M.; Khan, S.; Hussain, Z.; Kazi, M.; Ahmed Shah, S.; Mahmood, A.; Maniruzzaman, M. Biofunctional Hyaluronic Acid/ k-Carrageenan Injectable Hydrogels for Improved Drug Delivery and Wound Healing. Polymers 2022, 14, 376. https:/ / doi.org/10.3390/polym14030376

Academic Editor: Ying-Chieh Chen

Received: 10 December 2021

Accepted: 14 January 2022

Published: 19 January 2022

Publisher's Note: MDPI stays neutral with regard to jurisdictional claims in published maps and institutional affiliations.

Copyright: (c) 2022 by the authors Licensee MDPI, Basel, Switzerland. This article is an open access article distributed under the terms and conditions of the Creative Commons Attribution (CC BY) license (https:// creativecommons.org/licenses/by/ $4.0 /)$.
1 Department of Pharmacy, Abbottabad Campus, COMSATS University Islamabad, Abbottabad 22010, Pakistan; uzmaijaz92@gmail.com (U.I.); syedahmed.shah@superior.edu.pk (S.A.S.)

2 College of Pharmacy, University of Sargodha, Sargodha 40100, Pakistan; usman.minhas@uos.edu.pk

3 Department of Pharmacy, University of Malakand, Chakdara 18800, Pakistan; shahzebkhan@uom.edu.pk

4 Discipline of Pharmaceutical Sciences, School of Health Sciences, University of KwaZulu-Natal, Durban 4041, South Africa

5 Department of Pharmaceutics \& Pharmaceutical Technology, College of Pharmacy, University of Sharjah, Sharjah P.O. Box 27272, United Arab Emirates; zhussain@sharjah.ac.ae

6 Research Institute for Medical and Health Sciences (SIMHR), University of Sharjah, Sharjah P.O. Box 27272, United Arab Emirates

7 Department of Pharmaceutics, College of Pharmacy, King Saud University, P.O. Box 2457, Riyadh 11451, Saudi Arabia; mkazi@ksu.edu.sa

8 Department of Pharmaceutical Sciences, The Superior University, Lahore 54600, Pakistan

9 College of Pharmacy, Al Ain University, Abu Dhabi P.O. Box 112612, United Arab Emirates; Arshad.Mahmood@aau.ac.ae

10 Division of Molecular Pharmaceutics and Drug Delivery, Department of Molecular Pharmaceutics and Drug Delivery, College of Pharmacy, The University of Texas at Austin, Austin, TX 78712, USA; m.maniruzzaman@austin.utexas.edu

* Correspondence: msmarwat@cuiatd.edu.pk; Tel.: +92-3453650137; Fax: +92-0992-383441

Abstract: The in situ injectable hydrogel system offers a widespread range of biomedical applications in prompt chronic wound treatment and management, as it provides self-healing, maintains a moist wound microenvironment, and offers good antibacterial properties. This study aimed to develop and evaluate biopolymer-based thermoreversible injectable hydrogels for effective woundhealing applications and the controlled drug delivery of meropenem. The injectable hydrogel was developed using the solvent casting method and evaluated for structural changes using proton nuclear magnetic resonance, Fourier transforms infrared spectroscopy, thermogravimetric analysis, and scanning electron microscopy. The results indicated the self-assembly of hyaluronic acid and kappa-carrageenan and the thermal stability of the fabricated injectable hydrogel with tunable gelation properties. The viscosity assessment indicated the in-situ gelling ability and injectability of the hydrogels at various temperatures. The fabricated hydrogel was loaded with meropenem, and the drug release from the hydrogel in phosphate buffer saline (PBS) with a pH of 7.4 was $96.12 \%$, and the simulated wound fluid with a $\mathrm{pH}$ of 6.8 was observed to be at $94.73 \%$ at $24 \mathrm{~h}$, which corresponds to the sustained delivery of meropenem. Antibacterial studies on P. aeruginosa, S. aureus, and E. coli with meropenem-laden hydrogel showed higher zones of inhibition. The in vivo studies in Sprague Dawley (SD) rats presented accelerated healing with the drug-loaded injectable hydrogel, while $90 \%$ wound closure with the unloaded injectable hydrogel, $70 \%$ in the positive control group (SC drug), and $60 \%$ in the negative control group was observed (normal saline) after fourteen days. In vivo wound closure analysis confirmed that the developed polymeric hydrogel has synergistic wound-healing potential.

Keywords: bioactive polymers; thermosensitive hydrogel; biomaterials; wound repair and regeneration 


\section{Introduction}

Skin serves as the first line defensive barrier of a body against damage, pathogen invasion, and radiation and protects the human body against exogenous harmful factors [1,2]. When the skin becomes compromised, the healing process starts in a physiological fashion, consisting of four overlying stages: hemostasis, proliferation, inflammation, and remodeling to resolve the injury [3,4]. Wounds are the anatomical disruption of skin continuity [5] and constitute the disorganization of dermis composition, leading to the damaging of skin tissue chronically and acutely [6]. Wounds of chronic origin are a worldwide health issue as they do not follow the normal process of wound healing [7], which prolongs the healing time and increases the infection risk and causes serious complications [8]. Problems associated with chronic wound healing are poor oxygenation, age, diabetes, medications, smoking, infection, stress, alcoholism, obesity, and nutrition [9]. Numerous approaches are available for the treatment of wound infections such as microneedles, dressings, foams, films, membranes, liquid dosage forms, conventional therapy, and traditional and modern wound dressings [10]. Among these approaches, bioactive polymer-based thermoresponsive hydrogels consisting of biopolymers have revealed encouraging wound-healing efficacies [11].

Hydrogels are three-dimensional macromolecular networks that can absorb much more water than their dry form and can undergo swelling and expressively undergo volume expansion [12-14]. Thermosensitive hydrogels are the stimuli responsive approach, as they show responsiveness to change in the external environment (i.e., temperature); moreover, they undergo swelling due to changes in temperature $[2,12,15,16]$. These hydrogels exhibit polymers' shear-thinning properties and lead to the formation of gel from solution $[7,17]$. Thermosensitive hydrogels have sol-gel alteration above a certain temperature [18].

In the current study, we used an FDA-approved triblock copolymer (Pluronic F127) to form the injectable hydrogel. It is composed of a central hydrophobic chain of polypropylene oxide and two hydrophilic side chains of polyethylene oxide. It is used in regenerative medicine due to its ability to form thermoreversible micelles and gels [19]. Hyaluronic acid (HA) is composed of repeating units of $\mathrm{N}$-acetyl-d-glucosamine and d-glucuronic acid of nonsulfated glycosaminoglycan $[20,21]$. HA has a high water sorption capability; retains water; provides lubrication; has an effect on cellular functions such as adhesion, migration, and proliferation; and has various applications in the treatment of joints, tissue regeneration, cosmetics, and ocular surgery [21,22]. Kappa-carrageenan shows distinctive properties that make it an advantageous candidate for use in tissue engineering [23,24]. Hydrogels composed of $\kappa$-carrageenan increase cell proliferation and cartilage repair [25].

The progression of infection in the wound microenvironment is avoided by the use of broad-spectrum antibiotics such as meropenem, which is a $\beta$-lactam antibiotic with a broad spectrum of activity. Due to its reduced oral absorption and short half-life, i.e., $0.75-1 \mathrm{~h}$ [26], meropenem requires multiple intravenous injections after short intervals, i.e., every $3 \mathrm{~h}$ after reconstitution [27]. To improve stability, bioavailability, [28], and patient compliance, a new drug-delivery system for effective meropenem delivery is required [29]. The objective of this study was to develop and evaluate biopolymer-based thermoreversible injectable hydrogels for wound-healing applications and the controlled drug delivery of meropenem and to validate their self-healing potential to stimulate the in vivo wound-healing process in the excisional skin defect model.

In this project, we loaded meropenem, which has a broad spectrum of antibacterial properties, as the model drug, but the main emphasis of this project was to produce an injectable hydrogel composed of a novel biopolymers composite with tissue regeneration properties, i.e., hyaluronic acid and $\kappa$-carrageenan. Among all the conventional approaches, the bioactive polymer-based thermoresponsive hydrogel consisting of polysaccharides has revealed encouraging wound-healing efficacies. Therefore, we hypothesized that the biopolymer-based injectable hydrogel could stimulate tissue regeneration as well as promote the wound-closure process by providing abundant nutrients at the wound site and enhancing the wound-healing process by protecting the wound from infections. 
Thermoresponsive sol-gel transitions are beneficial, as they avoid surgical techniques and the complexity of developing biomaterials for transplantation at the site of action.

\section{Materials and Methods}

\subsection{Materials}

Kappa-carrageenan (Mw: 700 kDa) was purchased from TCI (Tokyo, Japan); hyaluronic acid (Mw: 8000-15,000 Da) was purchased from CarboSynth (Berkshire, UK); and Pluronic F-127 and F188 were obtained from Sigma-Aldrich (St. Louis, MO, USA), and were of BioReagent grade. Meropenem was obtained from Zhejiang Ray-bow pharma (Zhejiang, China). Sodium hydroxide, potassium dihydrogen phosphate, hydrochloric acid, potassium chloride, sodium chloride $(\mathrm{NaCl})$, and disodium hydrogen phosphate were purchased from Sigma-Aldrich (St. Louis, MO, USA).

\subsection{Methodology}

Development of Thermoreversible Hydrogel

The thermosensitive hydrogels were prepared by using the solvent casting method, also called the cold method [30]. Different solutions of Pluronic F-127, hyaluronic acid, and $\kappa$-carrageenan were prepared as shown in Table 1. Firstly, Pluronic F-127 was dissolved by adding weighed polymer to distilled water under constant stirring at $4{ }^{\circ} \mathrm{C}$. The resulting solution was marked as solution A. Hyaluronic acid was dissolved separately in distilled water and marked as solution B. A measured quantity of meropenem (1\%) was dissolved in solution B. Kappa-carrageenan, marked as solution C, was mixed and continuously stirred in distilled water at $60{ }^{\circ} \mathrm{C}$. Solutions ' $\mathrm{B}$ ' and ' $\mathrm{C}$ ' were mixed at room temperature with constant stirring. Then, this mixed solution was added to Pluronic F-127 solution dropwise and stirred continuously at $4^{\circ} \mathrm{C}$ until a homogeneous solution was obtained. The resultant mixture was transported to a glass vial and placed in a water bath maintained at $25^{\circ} \mathrm{C}$. The temperature of the water bath was increased gradually up to $37^{\circ} \mathrm{C}$ to monitor changes in the formulation $[25,31,32]$.

Table 1. Hyaluronic-acid-K-carrageenan-based F127 thermosensitive hydrogel feed composition.

\begin{tabular}{|c|c|c|c|c|c|c|}
\hline Formulation & $\begin{array}{c}\text { HA } \\
(\% w / w)\end{array}$ & $\begin{array}{c}\kappa-C \\
(\% w / w)\end{array}$ & $\begin{array}{c}\text { F127 } \\
(\% w / w)\end{array}$ & Meropenem & Gel Temp & Gel Time \\
\hline & & & & $(\% w / w)$ & $\left({ }^{\circ} \mathrm{C}\right)$ & (s) \\
\hline HC-1 & 3 & 0.2 & 21 & 1 & 36 & 13 \\
\hline HC-2 & 4 & 0.2 & 21 & 1 & 35 & 10 \\
\hline HC-3 & 5 & 0.2 & 21 & 1 & 34 & 8 \\
\hline $\mathrm{HC}-4$ & 4 & 0.1 & 21 & 1 & 33 & 9 \\
\hline HC-5 & 4 & 0.2 & 21 & 1 & 35 & 10 \\
\hline $\mathrm{HC}-6$ & 4 & 0.3 & 21 & 1 & 37 & 12 \\
\hline HC-7 & 4 & 0.2 & 21 & 1 & 36 & 15 \\
\hline HC-8 & 4 & 0.2 & 19 & 1 & 33 & 10 \\
\hline HC-9 & 4 & 0.2 & 21 & 1 & 31 & 6 \\
\hline
\end{tabular}

\subsection{In Vitro Characterization of Hydrogel}

\subsection{1. ${ }^{1} \mathrm{H}$ NMR and FTIR}

Hydrogels were analyzed using ${ }^{1} \mathrm{H}$ NMR (Ascend-400MHz, Bruker, Fällanden, Switzerland) operated at $400 \mathrm{MHz}$ for the structural evaluation of the developed formulations. Samples with a weight of $5 \mathrm{mg} / \mathrm{mL}$ were dissolved in deuterium oxide and deuterated chloroform, and tetramethylsilane (TMS) was used as an internal standard. Hydrogels were also analyzed for successful crosslinking using using a Nicolet 6700 FT-IR spectrometer (Thermo Scientific, Waltham, MA, USA). The thermosensitive hydrogel was lyophilized by employing LyoDry Freeze Dryers (Edwards Modulyo EF4K freeze dryer, Akribis Scientific Limited, Cheshire, UK), and the dried powder obtained was mixed with $\mathrm{KBr}$ in a ratio of 
1:100 and subjected to drying. Spectrum was observed at a wavelength of $4000-400 \mathrm{~cm}^{-1}$ using an FTIR spectrometer (Nicolet 6700, Thermofisher Scientific, Waltham, MA, USA).

\subsubsection{Thermogravimetric Analysis (TGA-DSC)}

Thermogravimetric analysis was performed to estimate the thermal stability of the injectable hydrogels and the polymers consumed for the development of gels. Samples were subjected to heating in an ELTRA thermogravimetric analyzer (TGA PT 1000 Linseis, ELTRA $\mathrm{GmbH}$, Haan, Gernany) at the temperature range of $25^{\circ} \mathrm{C}-500{ }^{\circ} \mathrm{C}$, with a uniform increment of $20{ }^{\circ} \mathrm{C}$ per minute at continuous nitrogen flow $(20 \mathrm{~mL} / \mathrm{min})$. The characterization was performed in triplicate to obtain the thermograms.

\subsubsection{Scanning Electron Microscopy (SEM)}

The surface morphology and structure of developed injectable hydrogels were determined by using SEM (Tungsten thermionic emission system, 3.5nm and 30keV, Vegas Tescan, Brno, Czech Republic). Samples were prepared for analysis by sprinkling the lyophilized sample powder on the double-sided adhesive tape fixed on the aluminum stub. These stubs were made up to a thickness of $\sim 300 \AA$ with gold coating provided with argon in a high-vacuum evaporator. The surface of the samples was cross-sectionally observed under a $10 \mathrm{kV}$ accelerator current.

\subsection{In Vitro Studies of Injectable Hydrogel}

\subsubsection{Gelation Time and Temperature}

The thermosensitive hydrogel was poured into vials and placed in the water bath (PolyScience WBE10A11B, PolyScience, Niles, IL, USA) at a temperature of $25^{\circ} \mathrm{C}$. The temperature of the water bath was increased slowly until it reached $37^{\circ} \mathrm{C}$. The flow of the hydrogel in the vial was checked. The time and temperature at which there was no flow in the solution were recorded as gelation time. Values obtained were the average of three determinations [33].

\subsubsection{Sol-Gel Phase Transition $\left(\mathrm{T}_{\text {sol-gel }}\right)$}

The tube-tilting technique was used for measuring the phase change temperature of the thermosensitive hydrogels. Hydrogels prepared with various ratios of hyaluronic acid, Pluronic F-127, and $\mathrm{k}$-carrageenan were transferred into glass vials. All vials were kept in a water bath at $25^{\circ} \mathrm{C}$ and the temperature was slowly increased to $37^{\circ} \mathrm{C}$. The thermosensitive behavior of developed formulations was evaluated by increasing the temperature [34,35].

\subsubsection{Optical Transmittance and Temperature-Induced Change}

Optical-transmittance and temperature-induced changes of the hydrogels were measured at different temperatures by using a spectrophotometer (UV-Visible). Transmittance was measured using cuvettes. The temperature of the water bath was slowly increased from $25^{\circ} \mathrm{C}$ to a maximum temperature of $40{ }^{\circ} \mathrm{C}$. Before being measured for transmittance, each sample was placed at each temperature for $5 \mathrm{~min}$ [36].

\subsubsection{Rheological Measurement}

An RM200 rotational rheometer (TA-Instruments, Nishigotanda, Japan) was used for the evaluation of the rheological properties of the thermosensitive hydrogels using spindle 5. Rheological behavior was analyzed at different temperatures, $25-34{ }^{\circ} \mathrm{C}$, to assess the effect of increasing temperature on the viscosity of the hydrogels $[33,37]$.

\subsubsection{Equilibrium Swelling Ratio}

The swelling behavior of the unloaded injectable hydrogels was analyzed in distilled water at $37^{\circ} \mathrm{C}$. All the formulations were properly weighed and placed in distilled water at $37^{\circ} \mathrm{C}$. At specific time intervals, results were recorded until equilibrium was maintained. 
The percentage swelling index or equilibrium swelling ratio (ESR) of the hydrogels was calculated using:

$$
\% \text { swelling ratio }=\frac{(\mathrm{Ws}-\mathrm{Wi})}{(\mathrm{Wi})}
$$

where "Wi" is the initial weight and "Ws" is the final weight for the sample.

\subsubsection{In Vitro Drug Loading}

Meropenem was loaded in the hydrogels by preparing a solution of $15 \mathrm{mg} / \mathrm{mL}$. The drug loading into the hydrogels was performed by adopting the preformulation loading method reported earlier. Briefly, the weighed amount of the drug was dissolved in polymeric hydrogel solution under continuous stirring for $30 \mathrm{~min}$ and the mixture was then set up for gel formation in a water bath at $37^{\circ} \mathrm{C}$ in glass vials.

\subsubsection{In Vitro Drug Release and Release Kinetics}

The dialysis bag method was used to carry out in vitro drug release, and a $10 \mathrm{kDa}$ dialysis bag was used. The drug release experiment was performed using an incubator shaker at the speed of $50 \mathrm{rpm}$ and a dialysis membrane. The drug release was performed by incubating the hydrogels in $10 \mathrm{~mL}$ of release medium at $37^{\circ} \mathrm{C}$ with continuous agitation. The release medium was composed of simulated wound fluid $(10 \mathrm{mM})$ with $\mathrm{pH} 6.3$ and phosphate buffer saline with $\mathrm{pH}$ 7.4. The simulated wound fluid (SWF) was composed of $3.3604 \mathrm{~g}$ sodium hydrogen carbonate, $5.8440 \mathrm{~g}$ sodium chloride, $0.2982 \mathrm{~g}$ potassium chloride, $33.00 \mathrm{~g}$ bovine albumin, $0.2775 \mathrm{~g}$ calcium chloride, and $1000 \mathrm{~mL}$ deionized water. Samples with a volume of $1 \mathrm{~mL}$ were collected at different time intervals (i.e., 0.5, 1, 2, 4, 6, $8,10,12,16,20$, and $24 \mathrm{~h}$ ) from the dissolution medium and replaced with $1 \mathrm{~mL}$ of fresh medium. The samples collected were then analyzed by a UV spectrophotometer (T80, PG Instruments Limited, Lutterworth, UK) at $\lambda_{\max } 298 \mathrm{~nm}$ [30]. The first-order, zero-order, Korsmeyer-Peppas, and Higuchi release kinetics models were applied to the drug release data of the injectable hydrogels.

\subsubsection{Antibacterial Activity}

Antibacterial activity of the thermosensitive hydrogels was evaluated against both Gram-positive (Staphylococcus aureus) and Gram-negative bacteria (Pseudomonas aeruginosa and Escherichia coli) using agar well technique. Agar plates were inoculated with the test microorganisms and four bores were created with the help of a borer. All four bores were separately labeled as drug-loaded injectable hydrogel, drug-unloaded injectable hydrogel, and positive and negative controls, respectively. After the test samples were placed in their respective bores, the plates were incubated for $18-24 \mathrm{~h}$ at $37^{\circ} \mathrm{C}$. After $24 \mathrm{~h}$ incubation, the zone of inhibition (ZOI) was measured using the following formula:

$$
\text { percentage inhibition }=\frac{\text { zone of inhibition of test sample }(\mathrm{mm})}{\text { zone of inhibition of standard drug }(\mathrm{mm})} \times 100
$$

\subsection{In Vivo Wound-Healing Analysis}

In vivo studies were conducted by using 24 Sprague Dawley rats, weighing 200-250 g and divided into four groups of six rats each. All four groups were individually labeled as the treatment group, the blank hydrogel group, and the positive and negative control groups, respectively. The treatment group was treated with drug-loaded thermoresponsive hydrogels, the blank group was treated with unloaded thermosensitive hydrogel, the negative control group was treated with normal saline, and the positive control group was treated with a subcutaneous injection of meropenem. All groups were provided with standard food, and their temperature conditions were maintained as per the Organization for Economic Co-operation and Development (OECD) guidelines. Rats were anesthetized by administering an intraperitoneal injection of xylazine $(15 \mathrm{mg} / \mathrm{kg})$ and ketamine $(85 \mathrm{mg} / \mathrm{kg})$. 
Dorsal hairs were shaved thoroughly, and a $1 \times 1 \mathrm{~cm}$ excisional wound was created using a surgical blade and forceps.

\subsection{Wound-Contraction Analysis and Histological Evaluation}

The wound closure area was measured and images of the wound site were obtained on day 1,7 , and 14 , whereas the percentage wound-closure rate was determined by using the following formula:

$$
\text { wound closure rate } \%=\left(A_{o}-A_{t}\right) / A_{o} \times 100
$$

where $A_{o}$ is the initial area of the wound and $A_{t}$ is an area of the wound at a designated time interval. All rats were sacrificed, and a histological evaluation of the wound was carried out by collecting tissue samples on the 1st, 7th, and 14th day after surgery. All samples were collected from the center of the wound and preserved in $10 \%$ formalin solution; later on, samples were fixed in paraffin wax. Samples were stained using eosin and hematoxylin dye, and histological images were obtained using a photomicroscope.

\section{Results}

\subsection{In Vitro Characterization of Hydrogel}

\subsection{1. ${ }^{1} \mathrm{H}$ NMR}

To investigate and confirm the successful formation of the carrageenan-based hyaluronic acid hydrogel, ${ }^{1} \mathrm{H}$ NMR and FTIR spectroscopy was performed. The ${ }^{1} \mathrm{H}$ NMR spectrum of F127 showed a distinctive $\mathrm{CH}_{3}$ signal of $\mathrm{PPO}$ at $\delta_{\mathrm{H}} 1.09 \mathrm{ppm}$ (Figure $1 \mathrm{~A}$ ).
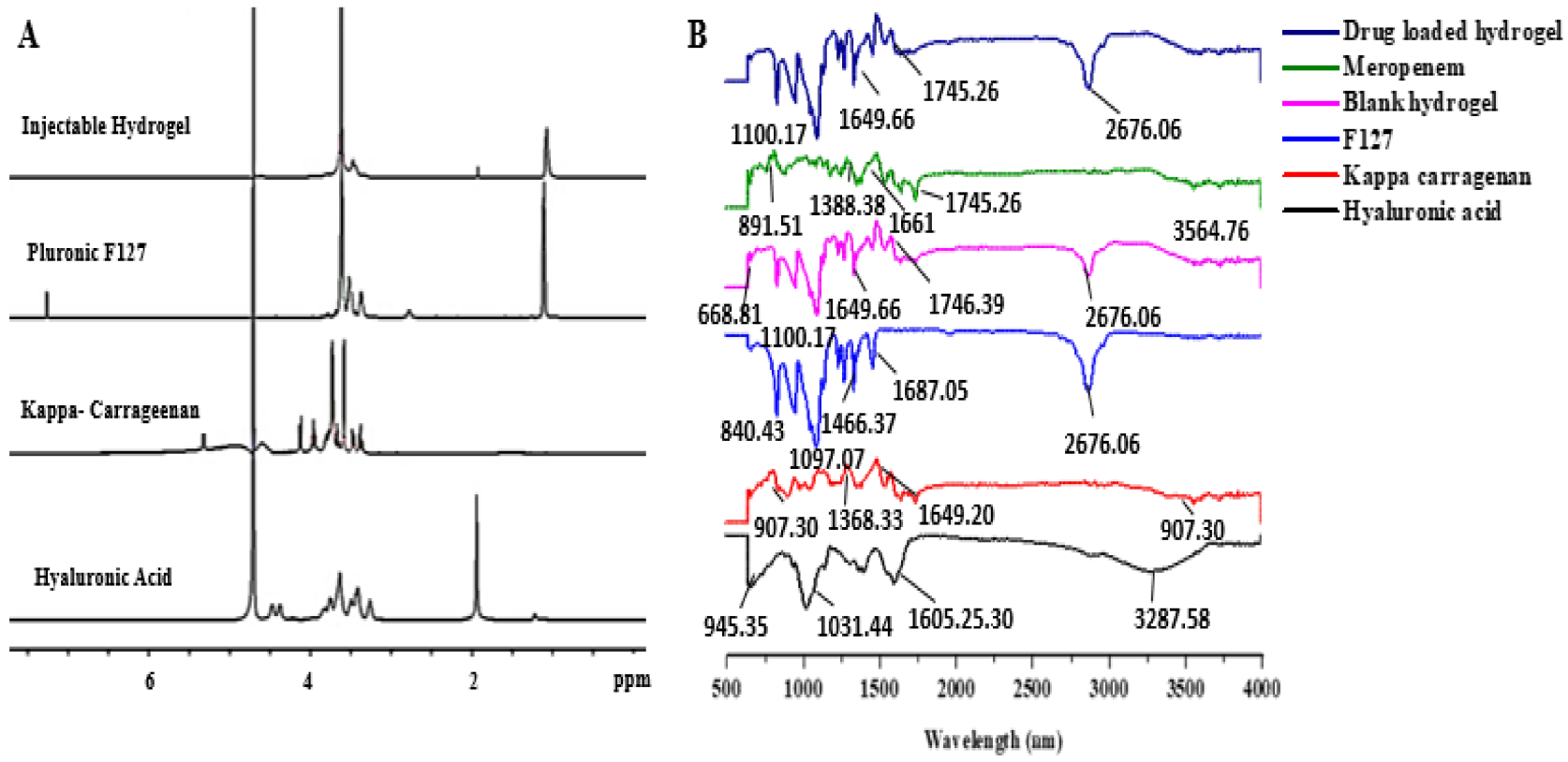

Figure 1. (A) ${ }^{1} \mathrm{H}$ NMR spectra of the injectable hydrogel, $\mathrm{k}$-carrageenan, F127, and hyaluronic acid; (B) FTIR spectrum of the drug-loaded hydrogel, meropenem, blank hydrogel, F127, k-carrageenan, and hyaluronic acid.

\subsubsection{FTIR}

The FTIR spectra (Figure 1B) of the $\mathrm{k}$-carrageenan showed that the bands appeared at $847.35,907.85,1189.78$, and $1208.65 \mathrm{~cm}^{-1}$ due to D-galactose-4-sulfate, glycosidic linkage, 3,6-anhydrous-D-galactose, and the ester sulfate stretching of the backbone of $\kappa$-carrageenan, respectively [33,34]. The bands at $1541.35,1564.70$, and $1649.20 \mathrm{~cm}^{-1}$ were due to functional groups such as carboxamide or carboxylate [35]. These bands are recognized by $\mathrm{C}=\mathrm{O}$ stretching in carboxamide functional groups and the asymmetric as well 
as symmetric stretching of carboxylate functional groups. Evidence of the stretching of -OH groups was the broad peak at $3250 \mathrm{~cm}^{-1}$ [36]. The FTIR spectroscopy of HA gave several broad bands. At $1031.44 \mathrm{~cm}^{-1}$, a band was observed which indicated the presence of C-O-C stretching $[37,38]$. The presence of the $\mathrm{C}-\mathrm{O}$ group with $\mathrm{C}=\mathrm{O}$ was indicated by the band at $1404.52 \mathrm{~cm}^{-1}$. Stretching vibrations were observed at $3250 \mathrm{~cm}^{-1}$, showing the presence of the OH group [39]. The FTIR of F127 showed bands at $959.38 \mathrm{~cm}^{-1}$, indicating the existence of an alkene group $(=\mathrm{C}-\mathrm{H})$. The presence of the ether group of the polymer was indicated by the band at $1097.07 \mathrm{~cm}^{-1}[40,41]$. Bands at $1341.34 \mathrm{~cm}^{-1}$ were associated with the presence of $\mathrm{CH}_{2}$ and $\mathrm{CH}_{3}$ groups.

\subsubsection{Thermogravimetric and Differential Scanning Calorimetry Thermographs}

The thermal stability and degradation of the Pluronic F127, HA, k-carrageenan, and the injectable hydrogel were estimated using thermogravimetric analysis by a TA analyzer. Figure $2 \mathrm{~A}, \mathrm{~B}$ represent the thermographs of the individual polymers and injectable hydrogel. The thermogram of the HA showed $15 \%$ weight loss at the temperature range of $50-100{ }^{\circ} \mathrm{C}$, which was associated with the removal of bounded water in the network [42], while the decomposition of the polysaccharide backbone occurred at the temperature range of $250-300{ }^{\circ} \mathrm{C}$, which resulted in $35 \%$ weight loss [43]. Similarly, the results from the diffractogram of the HA showed a broad exothermic peak at $100{ }^{\circ} \mathrm{C}$, corresponding to the dehydration of the HA. Another endothermic peak beginning at $150{ }^{\circ} \mathrm{C}$ and extending to $300{ }^{\circ} \mathrm{C}$ was due to the thermal degradation of the network structure.
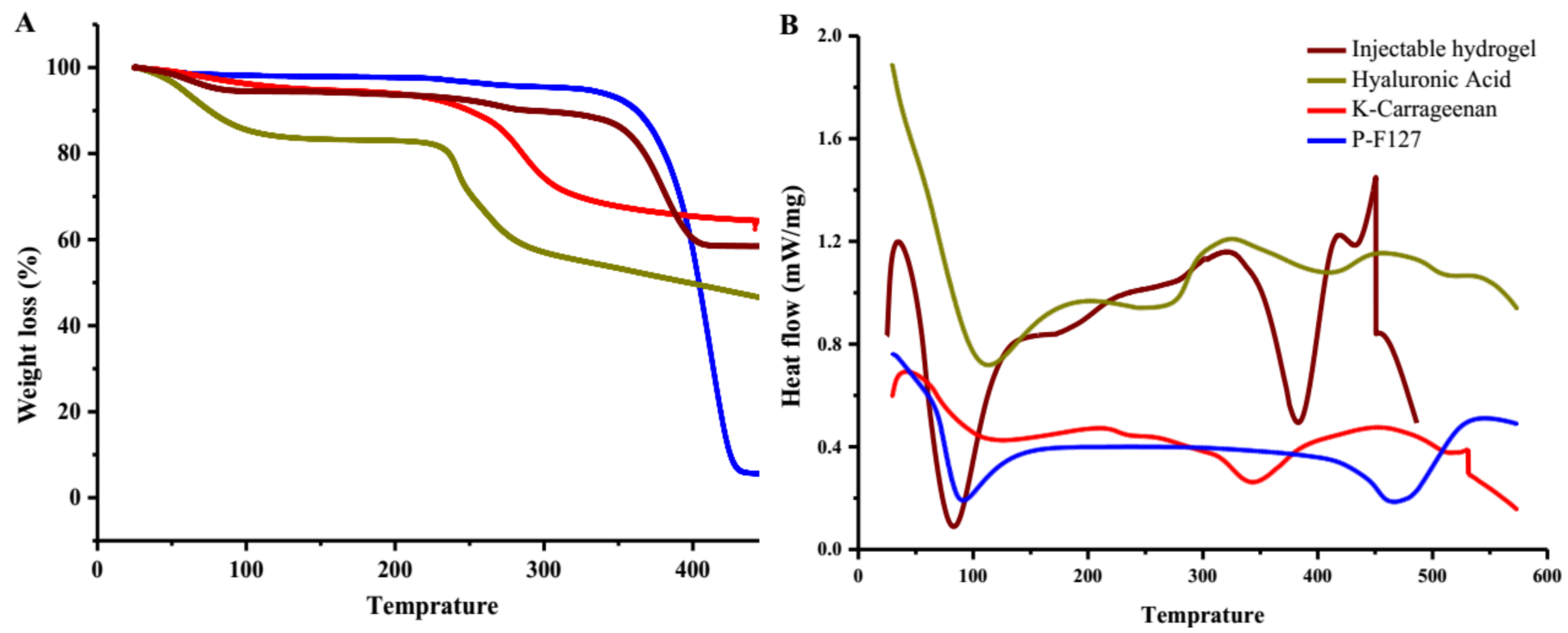

Figure 2. (A) Thermogram of F127, hyaluronic acid, k-carrageenan, and injectable hydrogel; (B) differential scanning calorimetry of the injectable hydrogel, hyaluronic acid, k-carrageenan, and F127.

The thermogram of the Pluronic F127 represented in Figure 2A demonstrated a weight loss of $10 \%$ at $250{ }^{\circ} \mathrm{C}$ that was attributed to the elimination of the bound water. The thermal degradation of the triblock polymer accounted for $80 \%$ weight loss at the temperature range of 390-450 ${ }^{\circ} \mathrm{C}[44,45]$. The diffractogram of the Pluronic F127 unveiled an endothermic band at $50{ }^{\circ} \mathrm{C}$ to $100{ }^{\circ} \mathrm{C}$ that was accredited to moisture loss, as illustrated in Figure 2B, and an endothermic band at $400-500{ }^{\circ} \mathrm{C}$, corresponding to the crystalline chain breakdown $[46,47]$.

\subsubsection{Scanning Electron Microscopy (SEM)}

SEM explains the surface morphology and diffusivity details of the synthesized samples. The surface morphology of the hydrogel is presented in Figure 3A. The SEM micro- 
graphs show that the synthesized hydrogel surface was porous, dense, and possessed a compact netlike structure. The physically cross-linked injectable hydrogel was examined under different magnifications, and tiny pores in the hydrogel were observed.
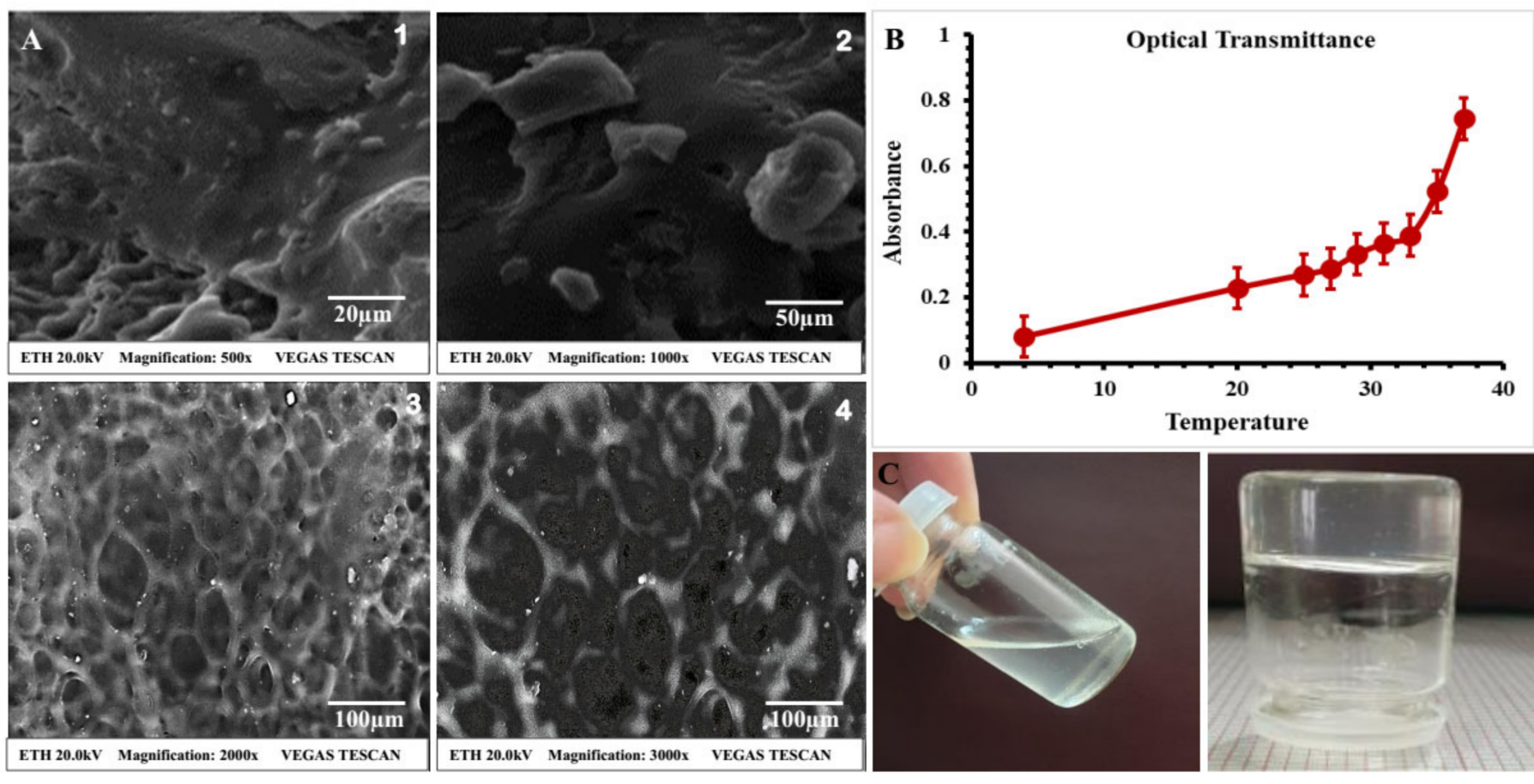

Figure 3. (A) Cross-sectional SEM micrograph views of injectable hydrogel at various magnifications to access the porosity in the network: (1) at a magnification of $500 \times$; (2) $1000 \times$ magnification; (3) $2000 \times$ magnification; and (4) magnification 3000×. (B) Optical transmittance and temperatureinduced changes of the thermosensitive hydrogel at various temperatures. (C) Visual representation of transparency of hydrogel and sol-gel phase transition in sol phase of prepared hydrogel and gel phase of prepared hydrogel.

\subsection{In Vitro Studies}

3.2.1. Physical Appearance and Clarity of Thermosensitive Hydrogel

The clarity and physical appearance of the hyaluronic-acid-K-carrageenan-based thermosensitive hydrogels are shown in Figure 3C.

\subsubsection{Gelation Time and Temperature}

The goal of this study was to illustrate the gelation time and temperature of the hyaluronic-acid-K-carrageenan-based F127 injectable hydrogels shown in Table 1. To achieve this goal, different concentrations of polymers were dissolved in distilled water and their gelation time and temperatures were recorded.

\subsubsection{Sol-Gel Phase Transition Analysis $\left(\mathrm{T}_{\text {sol-gel }}\right)$}

The fabricated hyaluronic-acid-k-carrageenan-based injectable hydrogels possessed thermoreversible properties. For injectable administration, the hydrogel system should be a liquid at normal room temperature for drug encapsulation and a gel at body temperature. The results in Figure 3C showed that the developed thermosensitive hydrogel could undergo a temperature-dependent change in mechanical strength, and the sol-gel transition was observed upon a change in temperature.

\subsubsection{Rheological Study}

The thermosensitive injectable hydrogel was measured for its rheological properties to check the flow of the formulated hydrogel, and the results are shown in Tables S1 and S2 
(Supplementary Data). The rheology of the hydrogel was assessed at two different temperatures with an increasing shear rate, i.e., $25^{\circ} \mathrm{C}$ and $34{ }^{\circ} \mathrm{C}$. The results indicated that the solution viscosity increased with the increase in temperature, i.e., the viscosity and temperature were directly proportional to each other, as shown in Figure 4A.
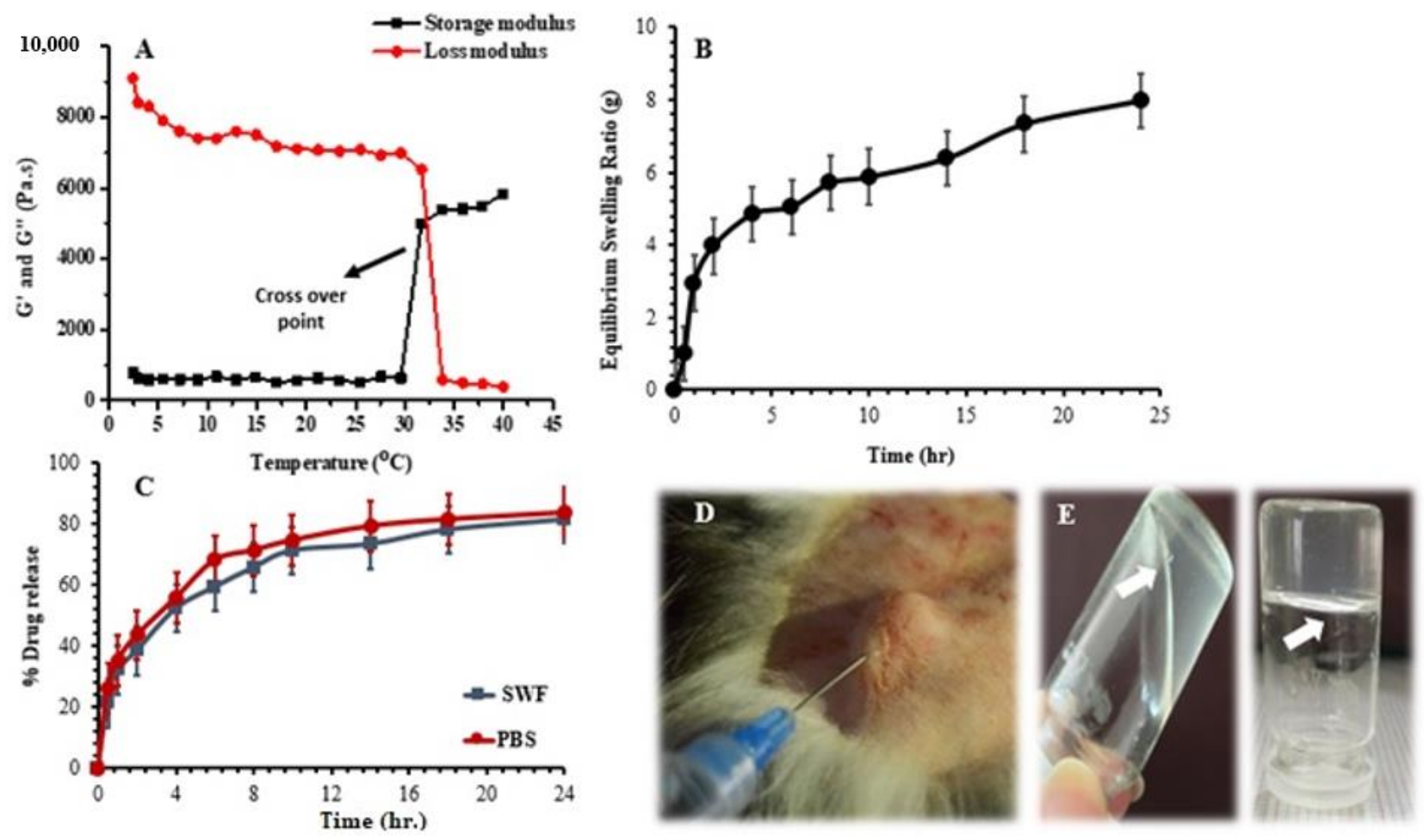

Figure 4. (A) Effect of temperature on changing the viscosity of injectable hydrogel by changing the shear rate; (B) equilibrium swelling ratio of thermosensitive injectable hydrogel; (C) percent drug release vs. time profile of injectable hydrogel; (D) in situ gelation after subcutaneous administration of injectable hydrogel in rabbits through 26-guage needle syringe; (E) pictorial representation of increasing viscosity due to which the gel faces difficulty in flowability.

\subsubsection{Optical Transmittance and Temperature-Induced Change}

The optical transmittance and temperature-induced changes of the hydrogels were measured at different temperatures by using a UV-vis spectrophotometer (UV-1280, Shimadzu, Kyoto, Japan), as shown in Figure 3B.

\subsubsection{Equilibrium Swelling Ratio (ESR)}

The swelling behavior of the synthesized injectable hydrogels was analyzed in distilled water at $37^{\circ} \mathrm{C}$ [48]. When water molecules come in contact with such hydrophilic groups, the network structure becomes hydrated due to the increased uptake of water molecules. The formulations encoded as HC-1, HC-2, and HC-3 with increasing hyaluronic acid concentrations, i.e., $3 \%, 4 \%$, and $5 \% w / v$, showed increased swelling. Swelling is greater in distilled water because of the ionization of the carboxyl group; consequently, the counterion concentration is increased within the network.

\subsubsection{In Vitro Drug-Release Studies}

Drug-release studies were conducted in simulated wound fluid (SWF) and phosphate buffer saline (PBS), as shown in Figure 4C. The percentage drug release in the SWF was calculated and was found to range between 81.542 and $94.736 \%$. The minimum drug release was observed for the formulation HC-9 $(81.542 \%)$, and the maximum release was observed for the HC-3 formulation (94.736\%). The drug release in PBS was slightly higher as compared to the SWF, i.e., it ranged from 83.76 to $96.12 \%$. The maximum drug release 
was observed in HC-7 and HC-9 $(83.76 \%)$. This indicated that the amount of meropenem released in PBS was slightly higher than the amount released in SWF.

\subsubsection{Drug-Release Kinetics}

Drug release from hydrogels is a complex process; therefore, to estimate the drugrelease kinetics, different kinetic models were used. The zero-order, first-order, Higuchi, and Korsmeyer-Pappas model results are shown in Table S3 (Supplementary Data). The drug-release mechanism of the hydrogel was explained by values close to the regression line, and it did not involve the mechanism of swelling.

\subsubsection{Antibacterial Activity}

The antibacterial activity of the thermosensitive hydrogels was measured by the agar well method [49]. A clear zone of inhibition (ZOI) was observed against S. aureus, P. aregnosa, and $E$. coli for the negative control (normal saline), positive control (meropenem), blank hydrogel, and drug-loaded hydrogel, as shown in Figure 5A,B.
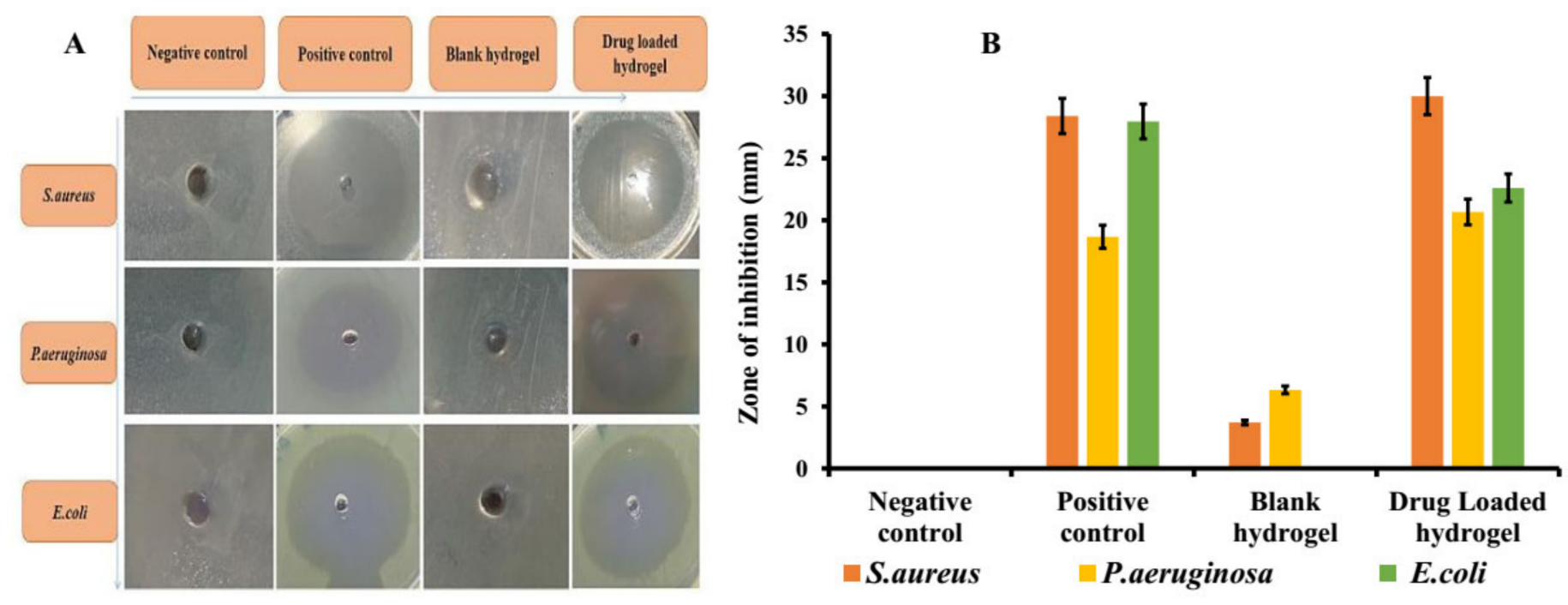

Figure 5. (A) Zone of inhibition against S. aureus, P. aregnosa and E. coli in positive control, negative control, blank hydrogel, and drug-loaded hydrogel; (B) graphical representation of zone of inhibition observed.

\subsection{In Vivo Wound-Healing Analysis \\ 3.3.1. Animal Studies}

The percentage wound closure was determined by measuring the area of the wound, as shown in Figure 6A. The percentage of wound closure of the blank injectable hydrogel, as well as the drug-loaded injectable hydrogel, was greater than that of the positive and negative control groups.

\subsubsection{Histological Examination}

Histological studies of the negative and positive controls, the blank hydrogel groups, and the drug-loaded hydrogel group were carried out at zero, seven, and fourteen days for wound-healing analysis, and the results are shown in Figure 6B. 


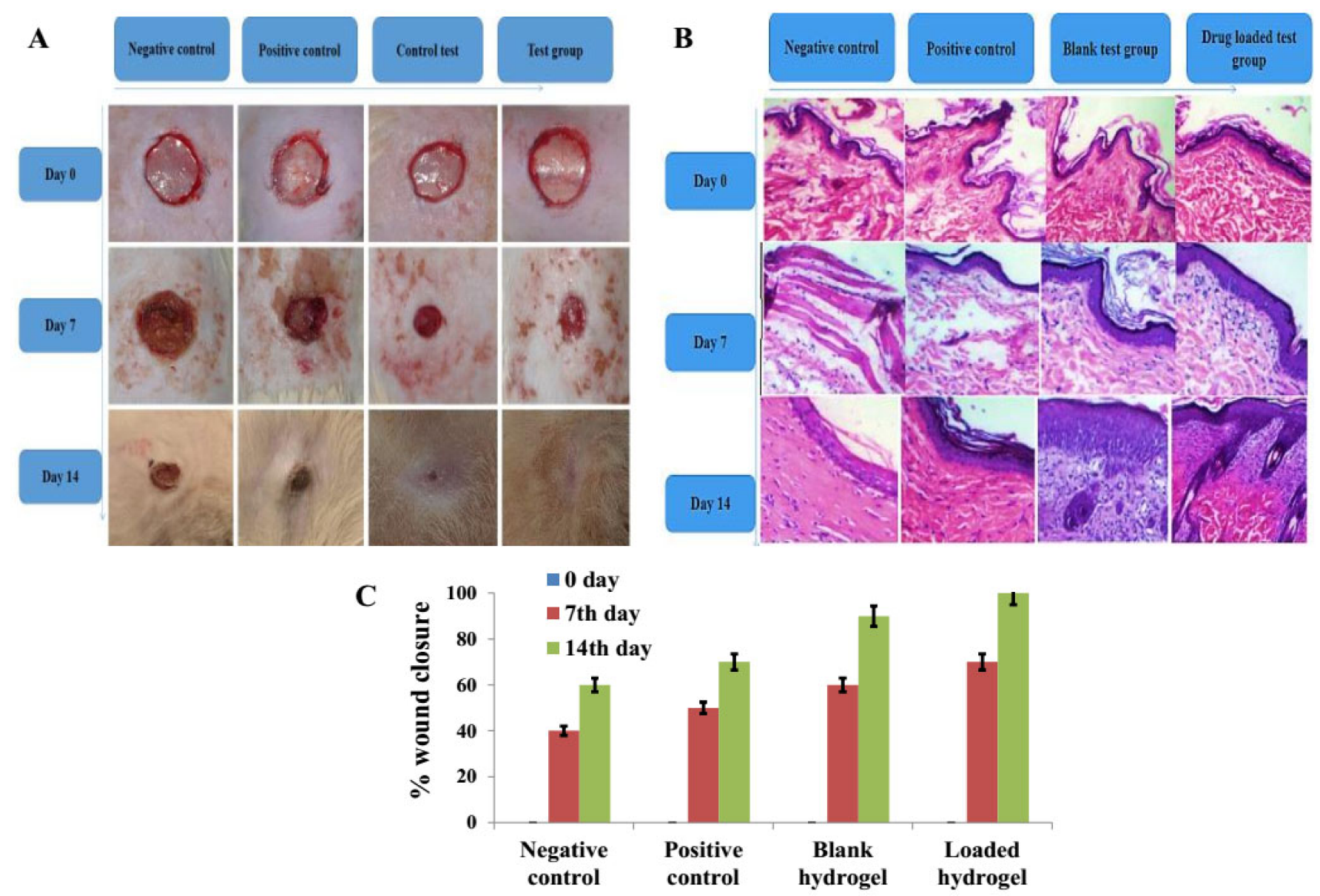

Figure 6. (A) \% Wound closure of different groups on day 0,7 , and 14 of the incision; (B) wound section histology of different groups on day 0,7 , and 14 , stained with hematoxylin and eosin stain; (C) macroscopic appearance of wounds postsurgery in four groups on day 0,7 , and 14 of the incision.

\section{Discussion}

\subsection{In Vitro Characterization of Hydrogel}

\subsection{1. ${ }^{1} \mathrm{H}$ NMR}

The peak at $\delta_{\mathrm{H}} 3.60 \mathrm{ppm}$ showed the presence of a hydroxymethyl proton [50-52]. A singlet was observed at $\delta_{\mathrm{H}} 1.94 \mathrm{ppm}$ in the ${ }^{1} \mathrm{H}$ NMR spectrum of the HA that indicated the presence of $N$-acetyl protons $\left(\mathrm{NCOCH}_{3}\right.$ ). The multiplets observed at $\delta_{\mathrm{H}} 3.20-3.90 \mathrm{ppm}$ showed the presence of protons from sugar moiety [53], and the $\mathrm{K}$-carrageenan spectrum revealed a peak at $\delta_{\mathrm{H}} 3.56 \mathrm{ppm}$ indicating O-methylene protons because of the presence of 3-linked 6-O-methyl-D-galactose residue present in K-carrageenan [54]. Mahmood et al. observed a similar effect with slight variation in chemical shift, which might be due to the difference in the source of the polymer obtained [55]. Compared with the spectra of the polymers, the injectable hydrogel showed a peak at $\delta_{\mathrm{H}} 1.07 \mathrm{ppm}$, which was also present in the spectrum of F127, belonging to the methyl group of PPO in F127. The signal at $\delta_{\mathrm{H}} 3.56 \mathrm{ppm}$ belonged to the $\mathrm{O}$-methylene group of $\mathrm{k}$-carrageenan, while the ${ }^{1} \mathrm{H} \mathrm{NMR}$ experiment was carried out as underwater suppression pulse program and the signals at $\delta_{\mathrm{H}}$ $1.94 \mathrm{ppm}$ for the HA were present in a small concentration. These observations suggested that no chemical interaction occurred between the polymers, and that the Pluronic F-127 was a major part of the self-assembled hydrogel which helped in the gel formation, while all the other components of the hydrogel were incorporated as minor part to enhance the tissue repair and regeneration. 


\subsubsection{FTIR}

The alkyl group presence was indicated by the formation of the band at $841.08 \mathrm{~cm}^{-1}$ in the formulation. In the case of the injectable hydrogel, bands occurred at 1240.17, 1341.62, 1466.16 , and $1540.88 \mathrm{~cm}^{-1}$. Some bands appeared at $1208.65,541.35$, and $1564.70 \mathrm{~cm}^{-1}$ in the K-carrageenan. The FTIR of the meropenem showed peaks at 1007.13, 1092.76, $1187.77,1256.89$, and $1388.38 \mathrm{~cm}^{-1}$, which corresponds to the presence of carbonyl CO stretching [56,57]. The band at 2877.10 showed the presence of $\mathrm{C}-\mathrm{H}$ stretching, the band at 1617.80 was due to $-\mathrm{NH}$ bending vibrations, and the peak at 1745.26 showed the presence of the carboxylic group in the structure. In the meropenem-loaded carrageenan-based hyaluronic acid hydrogel, the existence of meropenem was confirmed by the presence of its characteristic peaks responsible for the pharmacological effect.

\subsubsection{Thermogravimetric and Differential Scanning Calorimetry Thermographs}

The TGA of the $\mathrm{k}$-carrageenan revealed the two-stage degradation phenomena, as demonstrated in Figure 2A. The onset of the first stage began at room temperature and extended up to $100^{\circ} \mathrm{C}$, and was related to the loss of moisture from the hydrated polymer, as bioactive polymers have a strong affinity for water [58], whereas the total loss for the second degradation phase at the temperature range of $250-325{ }^{\circ} \mathrm{C}$ was $25 \%$, which corresponds to the degradation of the polysaccharide skeleton. The diffractogram of the $\mathrm{K}$-carrageenan is shown in Figure $2 \mathrm{~B}$, which represented the loss of free and bound water at $25-75^{\circ} \mathrm{C}$ and $100{ }^{\circ} \mathrm{C}$, respectively, while the exothermic peak at $310^{\circ} \mathrm{C}$ was considered as the $\mathrm{Tg}$, suggesting the decomposition of the D-galactose ring [59].

Additionally, Figure 2A,B show the thermograms and $\mathrm{Tg}$ of the freeze-dried injectable hydrogel. The gravimetric analysis revealed that the initial weight loss was low (i.e., $5 \%$ ) at $100{ }^{\circ} \mathrm{C}$, which was associated with the loss of bounded water, while only $40 \%$ of the total weight loss occurred at the degradation temperature $(\mathrm{Tg}) 350{ }^{\circ} \mathrm{C}$, indicating that the formulation had a higher thermal stability compared to the individual components HA, k-carrageenan, and Pluronic F127. Furthermore, the injectable hydrogel presented an exothermic peak at $50-75^{\circ} \mathrm{C}$, attributed to moisture loss, immediately followed by an endothermic peak extending from $75{ }^{\circ} \mathrm{C}$ to $400{ }^{\circ} \mathrm{C}$, which was attributed to the existence of a unique Tg curve that may have corresponded to successful self-assembly. This shift of the glass transition values of the injectable hydrogel compared to the polysaccharide polymers was related to physical crosslinking in the polymers.

\subsubsection{Scanning Electron Microscopy (SEM)}

Small pores appeared in the structure due to the F127, which supported the diffusion of water molecules around the structure. This also showed the greater influence of the polymers in the network structure and explained the greater interaction of the polymers within the hydrogel [60]. The expanded structure achieved a more stable and diffusible hydrogel, and the porous network could hold more water, facilitating the swelling of the hydrogel; similarly, the tiny pores on the surface suggested that the drug release from the hydrogel would occur in a sustainable manner [61].

\subsection{In Vitro Studies}

\subsubsection{Physical Appearance and Clarity of Thermosensitive Hydrogel}

The clarity and physical appearance of the HA-Cr-based F127 polymeric blend and the thermosensitive hydrogel were observed visually. The developed hydrogels had a transparent appearance and soft texture. A higher concentration of $\mathrm{k}$-carrageenan resulted in a slightly cloudy solution, while a greater concentration of hyaluronic acid enhanced the transparency of the developed hydrogels.

\subsubsection{Gelation Time and Temperature}

The gelation time of three hydrogels, i.e., HC-1, HC-2, and $\mathrm{HC}-3$, with different concentrations of hyaluronic acid $(3 \%, 4 \%$, and $5 \% w / v)$ were noted. It was observed that 
by increasing the concentration of hyaluronic acid, the required time for gelation decreased. HC-1 took $13 \mathrm{~s}$ to become a gel, whereas HC-2's gelation time was $10 \mathrm{~s}$ and HC-3's gelation time was $8 \mathrm{~s}$, as shown in Table 1 . The gelation temperatures of HC-1, HC-2, and HC-3 were $36{ }^{\circ} \mathrm{C}, 35^{\circ} \mathrm{C}$, and $34{ }^{\circ} \mathrm{C}$, respectively. The decrease in the gelation time indicated a microstructural change in the formulation due to the interaction between the hyaluronic acid and the F127 [62]. In an aqueous solution above critical micelle concentration, the selfassembly of copolymer molecules into micelles takes place. By increasing the temperature, the micelles pack together and overlap each other by hydrophobic interactions of the PPO blocks [63]. Low-molecular-weight hyaluronic acid, as was used in this study, allows the packing and movement of micelles, causing a change in the gelling properties [64].

The concentration of $\kappa$-carrageenan in the HC-4, HC-5, and HC-6 hydrogel formulations increased by $0.1 \%, 0.2 \%$, and $0.3 \% w / v$, respectively. It was observed that by increasing the concentration of $\kappa$-carrageenan, the required time for gelation increased. The gelation times of HC-4, HC-5, and HC- 6 were recorded $9 \mathrm{~s}, 10 \mathrm{~s}$, and $12 \mathrm{~s}$, respectively, while the gelation temperatures of HC-4, HC-5, and HC-6 were noted as $33^{\circ} \mathrm{C}, 35^{\circ} \mathrm{C}$, and $36^{\circ} \mathrm{C}$, respectively, as shown in Table 1. By increasing the concentration and temperature, the coil-to-helix structure of $\kappa$-carrageenan begins to shift towards a helix-to-coil conformation. Due to this transition, the melting of the helices and the structural rearrangement results in an increased gelation time and temperature [65].

The concentration of Pluronic F127 in the HC-7, HC-8, and HC-9 hydrogel formulations increased by $21 \%, 23 \%$, and $25 \% w / v$, respectively. Pluronic F127 in a concentration above $15 \%$ undergoes thermoreversible gelation, which is crucial for injectable administration [66]. It was observed that by increasing the concentration of F127, the gelation time and temperature decreased. The mechanism of the gelation of Pluronic F127 depends on the packing and entanglement of micelles. With the increase in temperature, micelles come into close contact and do not move. The micelles do not separate easily from each other due to micelle entanglements, and they form a rigid gel [67]. The critical micelle concentration and temperature were changed by the addition of hyaluronic acid and $\kappa$-carrageenan; hence, the gelation temperature of the developed hyaluronic-acid-k-carrageenan-based F127 hydrogel system should be higher than pure Pluronic F127. In the meropenem-loaded hydrogel, the concentration of meropenem was constant in all the formulations, from HC- 1 to HC-9, i.e., $1 \%$. A slight increase in the gelation time and temperature was observed after drug loading into the hydrogel. Meropenem is a hydrophilic drug, and when it was loaded into the F127-based thermosensitive hydrogel, it resulted in the increased hydrophilicity of the system, causing a slight change in its gelation properties [67].

\subsubsection{Sol-Gel Phase Transition Analysis ( $\mathrm{T}_{\text {sol-gel }}$ )}

The injectable hydrogel with a Pluronic F127 concentration lower than 15\% did not undergo gelation at body temperature. Pluronic F127 is composed of polypropylene oxide and polyethylene oxide (PEO-PPO-PEO). PEO side chains are hydrophilic, while the PPO in the center is hydrophobic [68]. The hydrophilic PPO core becomes exposed, resulting in gelation and increased chain entanglements. When the concentration of F127 is increased, these chain entanglements also increase, resulting in the hydrogel. The developed hydrogel responded to temperature change, achieving the flowing phase at $25^{\circ} \mathrm{C}$ and nonflow state at $37^{\circ} \mathrm{C}$, thus conforming to sol-gel phase transition. Sol-gel transition is an ideal parameter for injectable hydrogel, while instant gelation leads to the clogging of the syringe before administration

\subsubsection{Rheological Study}

The hydrophilic interactions were overcome by hydrophobic interactions when the temperature was increased above LCST, resulting in a dehydrated state with an increase in viscosity $[69,70]$. The storage moduli and loss moduli of the hyaluronic-acid-k-carrageenan $(\mathrm{HA}-\mathrm{KC}$ )-based injectable hydrogel are presented in Figure $4 \mathrm{~A}$. The grafting process of the injectable hydrogels was assumed to be over when the $G^{\prime}$ extended to a plateau 
formation. The grafting of the $\mathrm{k}$-carrageenan and HA to the F127 in the HA- $\mathrm{kC}$ hydrogel was completed when the $G^{\prime}$ extended the $G^{\prime \prime}$, where the cross-over point represents the gelation. The crossover point was situated at $32{ }^{\circ} \mathrm{C}$, which corresponded to an upsurge in the viscosity with the function of changing temperature. Moreover, the increasing temperature led to a reduction in the time it took to reach the plateau value and an increase in the storage modulus [71]. Additionally, the damping factor of the samples was between 0.001 and 0.003 . The damping factor for the $\mathrm{HA}-\mathrm{KC}$ hydrogel was low, attributable to the viscoelastic behavior of injectable hydrogels [72,73].

\subsubsection{Optical Transmittance and Temperature-Induced Change}

The transmittance of the fabricated hydrogel was measured by using cuvettes. The developed thermosensitive hydrogel demonstrated an increase in absorbance beyond the critical gelation temperature $\left(\geq 32{ }^{\circ} \mathrm{C}\right)$. The increase in absorbance was due to the larger particle size at a temperature higher than LCST. It was observed that below LCST, the hydrogel solution was transparent due to the hydrophilic interactions, which indicated the uniform solubility of the added components. After increasing the temperature, the hydrophilic interactions were overcome by hydrophobic interactions, resulting in the increased size of the components and the turbidity of the solution [74].

\subsubsection{Equilibrium Swelling Ratio (ESR)}

Upon ionization, the osmotic pressure difference arose within the solution and outside the gel, resulting in greater swelling [75,76]. When the concentration of $k$-carrageenan was increased, i.e., $0.1 \%$ in HC- $4,0.2 \%$ in HC-5, and $0.3 \%$ in HC-6, it was observed the swelling of the hydrogel also increased, as shown in Figure 4B. The sulfate groups in the $\mathrm{K}$-carrageenan structure are ionizable, and they become deprotonated to produce $\mathrm{OSO}_{3}{ }^{-}$in the system. Therefore, as the concentration of the polymer increased, the number of these negatively charged groups also increased, resulting in greater repulsion and increased swelling. Negatively charged groups on different chains induce electrostatic repulsion, due to which the distance between the chains also increases. As a result, the space between the network becomes larger and more permeable to larger molecules. Hence, a large amount of water can penetrate the polymeric network, which results in greater swelling [76]. On the other hand, upon increasing the concentration of F127, a decrease in swelling was observed, as shown in Figure 4B, possibly because the PEO side chains are hydrophilic while the PPO in the center is hydrophobic in the structure of Pluronic F127. When hydrogen bonds break, the hydrophilic side chains become weak [77]; as a result, when the concentration of F127 was increased, these chain entanglements also increased, resulting in greater gel strength. Less water could penetrate inside the gel, which ultimately resulted in less swelling. Upon increasing the concentration of F127, the hydrophobic groups in the center involved in intermolecular entanglements increased, creating a transient 3D polymer network. This phenomenon provided strength to the gel, decreasing swelling by hindering the passage of water molecules [78].

\subsubsection{In Vitro Drug-Release Studies}

In the formulations where the hyaluronic acid concentration was increased from $3 \%$ $w / v$ to $5 \% w / v$ in PBS and SWF, an increase in the concentration of HA to $5 \%$ resulted in better drug release. The ionization of the carboxyl group influences the counterion concentration, and with an increased HA concentration more counterions are generated, resulting in the creation of an osmotic pressure difference between the solution within and outside the gel, which is responsible for better drug release [79]. Increasing the concentrations of $\mathrm{k}$-carrageenan from $0.1 \% w / v$ in HC-4 to $0.2 \%$ w $/ v$ in HC-5 and $0.3 \%$ $w / v$ in HC- 6 changed the charge density on the hydrogel network due to the presence of ionic groups, i.e., $\mathrm{COO}^{-}$and $\mathrm{OSO}_{3}{ }^{-}$. As the concentration of carrageenan increased, these groups are repelled by each other as well as solvent molecules, resulting in the swelling of the hydrogel and increased drug release [80]. The deprotonation of the $\mathrm{OSO}_{3} \mathrm{H}$ and 
$\mathrm{COOH}$ groups also occurs, resulting in the maximum ionization of these groups, which causes increased swelling and drug release from the matrix [81]. Drug-release studies were performed on the hydrogel with increasing concentrations of F127 from $21 \% w / v$ in HC-7 to $23 \% w / v$ in HC-8 and $25 \% w / v$ in HC-9. It was observed that in both dissolution media, the drug release decreased with an increasing F127 concentration; this was because of the influence of the hydrophobic groups that are present in the F127 structure [82]. When its concentration increased, micelle formation also increased, due to the extensive interaction between the hydrophobic groups which in turn thickened the gel layer and hindered the drug release from the gel matrix [83].

\subsubsection{Drug-Release Kinetics}

The Higuchi model shows a high $\mathrm{R}^{2}$ value, so it better fit the regression line and more effectively explained the drug-release mechanism from the matrix [84]. The Higuchi model is based on two hypotheses: firstly, the drug concentration present in the matrix is greater than the drug solubility; secondly, the flow of the drug in the matrix system is one-dimensional. According to this model, the drug particle size is lower than the system thickness, and there is constant diffusion of the drug during its release [84]. The Korsmeyer-Peppas model also explained the drug release from the polymer. The value of " $n$ " was calculated by plotting the values of the release data in the Korsmeyer-Peppas model sheet. If the value of $\mathrm{n}$ was equal to or less than $0.45(\mathrm{n} \leq 0.45)$, then the Fickian diffusion model was followed.

\subsubsection{Antibacterial Activity}

Figure 5A depicts that the ZOI observed against S. aureus was $28.4 \mathrm{~mm}$ for the positive control, whereas no zone was observed for the negative control. Moreover, the ZOI obtained for the blank injectable hydrogel was $3.7 \mathrm{~mm}$, whereas a zone of $30 \mathrm{~mm}$ was observed for the drug-loaded injectable hydrogel. For $P$. areginosa, no inhibition zone was observed in the negative control group, whereas ZOIs of $18.66 \mathrm{~mm}, 6.33 \mathrm{~mm}$, and $20.66 \mathrm{~mm}$ were observed in the positive control, blank hydrogel, and drug-loaded hydrogel, respectively. In the case of E. coli, the ZOIs observed for the blank and drug-loaded hydrogel were $27.96 \mathrm{~mm}$ and $22.6 \mathrm{~mm}$, respectively. On the other hand, no ZOI was observed for the blank hydrogel and negative control groups. The study results demonstrated that the blank injectable hydrogels had little or no antibacterial activity, while clear ZOIs were observed against all the bacterial strains in the drug-loaded injectable hydrogel, as shown in Figure 5A. It was observed from the study results that the drug-loaded membrane showed a larger ZOI against the Grampositive strain compared to the Gram-negative strain, which might have been due to the cell-wall structure of Gram-negative bacteria. Gram-negative bacteria contain an outermost membrane of peptidoglycan, which protects them against environmental damage.

\subsection{In Vivo Wound-Healing Analysis}

\subsubsection{Animal Studies}

During the first week of the wound-healing analysis, little inflammation in all the rats was observed [85]. No signs of infection were observed, and crusts started to form by the end of the first week, which indicated the epithelization process in all groups. On day 14, both the positive and negative control groups showed slower epithelialization, with $70 \%$ and $60 \%$ wound closure, respectively. Contrastingly, a marked reduction in wound size was observed in the blank and drug-loaded hydrogel groups, with $90 \%$ and $100 \%$ wound closure, respectively. The fast healing potential displayed in the blank and drug-loaded hydrogel groups was attributed to the presence of HA and $\kappa$-carrageenan, which has an effect on the different stages of wound healing, such as migration, adhesion, and proliferation [21,22]. Moreover, the sustained release of meropenem prevented the wound from secondary infection and aided in faster healing. 


\subsubsection{Histological Examination}

At zero days, very few inflammatory cells were observed, which was referred to as the chronic inflammatory phase in all four groups. On the seventh day of the experiment, small blood vessels were emerging in the wound microenvironment in the drug-loaded hydrogel group and a negligible amount of inflammatory cells were seen compared to the negative and positive control groups, whereas the unloaded injectable hydrogel group also showed few inflammatory cells, showing that the inflammatory phase was complete after seven days in the drug-loaded injectable group $[86,87]$. Histological analysis confirmed the presence of abundant fibroblasts and granulating cells in the injectable hydrogel groups, while few were present in the control groups [88].

On the fourteenth day, there were still several neovascularization and inflammatory cells present in the other two groups, particularly the negative control group. The drugloaded injectable hydrogel group showed a thicker granulating layer than the unloaded injectable group, while the negative control showed a thinner granulating layer than the positive control group. Angiogenesis was observed in the drug-loaded and drugunloaded injectable hydrogel groups, while it was still absent in the control groups. The histological analysis results showed abundant mature collagen in the drug-loaded and unloaded hydrogel groups, whereas immature collagen was found in the positive and negative groups. On the 14th day, sebaceous glands, sweat glands, and hair follicles were observed, as shown in Figure 6B, whereas no such glands were observed in the positive and negative control groups. The histopathology results showed that in the control groups, the healing process was slower and delayed, while the hydrogel groups showed faster healing by employing re-epithelialization and ECM deposition and remodeling.

\section{Conclusions}

In this research, an in situ injectable biopolymer-based hydrogel network was developed to stimulate the wound-healing cascade in an excisional wound model. For improved drug delivery and wound healing, the cold method was employed, using Pluronic F127 and bioactive polymers with commendable biocompatibility to form in situ injectable hydrogels with prompt gelation and tunable mechanical properties. The structure of the cross-linked injectable hydrogel was confirmed through FTIR. The thermal stability was evaluated through TGA and DSC, while the hydrogel's porous structure was analyzed using SEM. Swelling studies showed that the system swelled accurately, while release studies demonstrated the efficient release of the meropenem from the thermosensitive hydrogel matrix. All the results proved that the proposed hydrogel solution could be useful for wound healing and that this developed hydrogel has the potential to act as a bioactive wound healer for the synergistic improvement of impaired skin wound healing.

Supplementary Materials: The following supporting information can be downloaded at: https: / / www.mdpi.com/article/10.3390/polym14030376/s1, Table S1: Rheological study results for thermosensitive injectable hydrogel at $25{ }^{\circ} \mathrm{C}$, Table S2: Rheological study results for thermosensitive injectable hydrogel at $34^{\circ} \mathrm{C}$, Table S3: Release kinetic models of injectable hydrogel with changing HA, kappa-carrageenan, and F127 concentration.

Author Contributions: Conceptualization, M.S. and U.I.; software, S.A.S.; validation, S.K., Z.H., and M.K.; formal analysis and investigation, M.U.M. and U.I.; resources, A.M. and M.M.; data curation, M.S. and S.A.S.; writing-original draft preparation, U.I.; writing-review and editing, M.S.; visualization, S.K. and M.K.; supervision, M.S. and S.A.S.; project administration, M.K.; funding acquisition, M.M. All authors have read and agreed to the published version of the manuscript.

Funding: The authors are thankful to the Researcher Supporting Project (number RSP-2021/301) at King Saud University, Riyadh, Saudi Arabia.

Institutional Review Board Statement: Healthy, adult male SD rats with an average weight of $200 \pm 10 \mathrm{~g}$ were utilized for the in vivo wound-healing analysis after gaining approval from the departmental ethical committee (COM-SD-1587/PHM), COMSATS University Islamabad, Abbottabad Campus. 
Informed Consent Statement: Informed consent was obtained from all subjects involved in the study.

Data Availability Statement: Not applicable.

Acknowledgments: The authors acknowledge the Higher Education Commission of Pakistan for the financial support through Project No. 5296/Federal/ NRPU/R\&D/HEC/2016. The authors are thankful to Researcher Supporting Project (number RSP-2021/301) at King Saud University, Riyadh, Saudi Arabia.

Conflicts of Interest: The authors declare that they have no conflict of interest.

\section{References}

1. Jayaramudu, T.; Varaprasad, K.; Reddy, K.K.; Pyarasani, R.D.; Akbari-Fakhrabadi, A.; Amalraj, J. Alginate-based composite materials for wound dressing application: A mini review. Carbohydr. Polym. 2020, 236, 116025.

2. Shah, S.A.; Sohail, M.; Khan, S.; Minhas, M.U.; de Matas, M.; Sikstone, V.; Kousar, M. Biopolymer-based biomaterials for accelerated diabetic wound healing: A critical review. Int. J. Biol. Macromol. 2019, 139, 975-993. [CrossRef] [PubMed]

3. Lazarus, G.S.; Cooper, D.M.; Knighton, D.R.; Margolis, D.J.; Percoraro, R.E.; Rodeheaver, G. Definitions and guidelines for assessment of wounds and evaluation of healing. Wound Repair Regen. 1994, 2, 165-170. [CrossRef]

4. $\quad$ Singer, A.J.; Clark, R. Cutaneous wound healing. N. Engl. J. Med. 1999, 341, 738-746. [CrossRef]

5. Karadsheh, M.; Nelson, J.; Rechner, B.; Wilcox, R. Application of a Skin Adhesive to Maintain Seal in Negative Pressure Wound Therapy: Demonstration of a New Technique. Wounds 2017, 29, E106-E110.

6. Qin, Y.; Hu, H.; Luo, A. The conversion of calcium alginate fibers into alginic acid fibers and sodium alginate fibers. J. Appl. Polym. Sci. 2006, 101, 4216-4221. [CrossRef]

7. Crane, M.J.; Henry, W.L., Jr.; Tran, H.L.; Albina, J.E.; Jamieson, A.M. Assessment of Acute Wound Healing using the Dorsal Subcutaneous Polyvinyl Alcohol Sponge Implantation and Excisional Tail Skin Wound Models. J. Vis. Exp. 2020, 157, 32281981. [CrossRef] [PubMed]

8. James, G.A.; Swogger, E.; Wolcott, R.; Pulcini, E.; Secor, D.; Sestrich, P. Biofilms in chronic wounds. Adv. Wound Care 2008, 16, 37-44. [CrossRef] [PubMed]

9. Guo, S.A.; DiPietro, L.A. Factors affecting wound healing. J. Dent. Res. 2010, 89, 219-229. [CrossRef] [PubMed]

10. Boateng, J.S.; Matthews, K.H.; Stevens, H.N.; Eccleston, G.M. Wound healing dressings and drug delivery systems: A review. J. Pharm. Sci. 2008, 97, 2892-2923. [CrossRef] [PubMed]

11. Sabbagh, F.; Kim, B.S. Recent advances in polymeric transdermal drug delivery systems. J. Control Release 2022, $341,132-146$. [CrossRef]

12. Ahmad, U.; Sohail, M.; Ahmad, M.; Minhas, M.U.; Khan, S.; Hussain, Z.; Shah, S.A. Chitosan based thermosensitive injectable hydrogels for controlled delivery of loxoprofen: Development, characterization and in-vivo evaluation. Int. J. Biol. Macromol. 2019, 129, 233-245. [CrossRef] [PubMed]

13. Shah, S.A.; Sohail, M.; Minhas, M.U.; Khan, S.; Hussain, Z.; Mahmood, A.; Mahmood, A. pH-responsive CAP-co-poly (methacrylic acid)-based hydrogel as an efficient platform for controlled gastrointestinal delivery: Fabrication, characterization, in vitro and in vivo toxicity evaluation. Drug Deliv. Transl. Res. 2019, 9, 555-577. [CrossRef] [PubMed]

14. Zia, M.A.; Sohail, M.; Minhas, M.U.; Sarfraz, R.M.; Khan, S.; de Matas, M.; Kousar, M. HEMA based pH-sensitive semi IPN microgels for oral delivery; a rationale approach for ketoprofen. Drug Dev. Ind. Pharm. 2020, 46, 272-282. [CrossRef] [PubMed]

15. Qu, J.; Zhao, X.; Liang, Y.; Zhang, T.; Ma, P.X.; Guo, B.J.B. Antibacterial adhesive injectable hydrogels with rapid self-healing, extensibility and compressibility as wound dressing for joints skin wound healing. Biomaterials 2018, 183, 185-199. [CrossRef] [PubMed]

16. Lee, B.H.; West, B.; McLemore, R.; Pauken, C.; Vernon, B.L.J.B. In-situ injectable physically and chemically gelling NIPAAm-based copolymer system for embolization. Biomacromolecules 2006, 7, 2059-2064. [CrossRef] [PubMed]

17. Qu, J.; Zhao, X.; Ma, P.X.; Guo, B. pH-responsive self-healing injectable hydrogel based on N-carboxyethyl chitosan for hepatocellular carcinoma therapy. Acta Biomater. 2017, 58, 168-180. [CrossRef]

18. Teotia, A.; Sami, H.; Kumar, A. Thermo-responsive polymers: Structure and design of smart materials. In Switchable and Responsive Surfaces and Materials for Biomedical Applications; Elsevier: Amsterdam, The Netherlands, 2015; pp. 3-43.

19. Pitto-Barry, A.; Barry, N.P. Pluronic ${ }^{\circledR}$ block-copolymers in medicine: From chemical and biological versatility to rationalisation and clinical advances. Polym. Chem. 2014, 5, 3291-3297. [CrossRef]

20. Hassan, A.; Abdel-Mohsen, A.; Elhadidy, H. Adsorption of arsenic by activated carbon, calcium alginate and their composite beads. Int. J. Biol. Macromol. 2014, 68, 125-130. [CrossRef] [PubMed]

21. Zhang, H.; Zhang, K.; Zhang, X.; Zhu, Z.; Yan, S.; Sun, T. Comparison of two hyaluronic acid formulations for safety and efficacy (chase) study of knee osteoarthritis: A multicenter, randomized, double-blind, 26 week non-inferiority trial comparing durolane ${ }^{\circledR}$ to $\operatorname{artz}^{\circledR}$. Osteoarthr. Cartil. 2014, 22, S397. [CrossRef]

22. Park, S.-N.; Lee, H.J.; Lee, K.H.; Suh, H.J.B. Biological characterization of EDC-crosslinked collagen-hyaluronic acid matrix in dermal tissue restoration. Biomaterials. 2003, 24, 1631-1641. [CrossRef] 
23. Campo, V.L.; Kawano, D.F.; da Silva, D.B., Jr.; Carvalho, I.J.C.P. Carrageenans: Biological properties, chemical modifications and structural analysis-A review. Carbohydr. Polym. 2009, 77, 167-180. [CrossRef]

24. Pereira, R.C.; Scaranari, M.; Castagnola, P.; Grandizio, M.; Azevedo, H.S.; Reis, R. Novel injectable gel (system) as a vehicle for human articular chondrocytes in cartilage tissue regeneration. J. Tissue Eng. Regen. Med. 2009, 3, 97-106. [CrossRef] [PubMed]

25. Popa, E.G.; Caridade, S.G.; Mano, J.F.; Reis, R.L.; Gomes, M.E.J.J.; Medicine, R. Chondrogenic potential of injectable k-carrageenan hydrogel with encapsulated adipose stem cells for cartilage tissue-engineering applications. J. Tissue Eng. Regen. Med. 2015, 9, 550-563. [CrossRef]

26. Mouton, J.W.; van den Anker, J.N.J.C.p. Meropenem clinical pharmacokinetics. Clin. Pharmacokinet. 1995, 28, 275-286. [CrossRef]

27. Tanaka, S.; Matsui, H.; Kasai, M.; Kunishiro, K.; Kakeya, N.; Shirahase, H. Novel prodrugs of meropenem with two lipophilic promoieties: Synthesis and pharmacokinetics. J. Antibiot. 2011, 64, 233. [CrossRef] [PubMed]

28. Teitelbaum, A.M.; Meissner, A.; Harding, R.A.; Wong, C.A.; Aldrich, C.C.; Remmel, R.P.J.B. Synthesis, pH-dependent, and plasma stability of meropenem prodrugs for potential use against drug-resistant tuberculosis. Bioorg. Med. Chem. 2013, 21, 5605-5617. [CrossRef]

29. Yang, J.-A.; Yeom, J.; Hwang, B.W.; Hoffman, A.S.; Hahn, S.K. In situ-forming injectable hydrogels for regenerative medicine. Prog. Polym. Sci. 2014, 39, 1973-1986. [CrossRef]

30. Jung, Y.-S.; Park, W.; Park, H.; Lee, D.-K.; Na, K. Thermo-sensitive injectable hydrogel based on the physical mixing of hyaluronic acid and Pluronic F-127 for sustained NSAID delivery. Carbohydr. Polym. 2017, 156, 403-408. [CrossRef]

31. Yeh, M.-Y.; Zhao, J.-Y.; Hsieh, Y.-R.; Lin, J.-H.; Chen, F.-Y.; Chakravarthy, R.D.; Hung, S.-C.J.R.A. Reverse thermo-responsive hydrogels prepared from Pluronic F127 and gelatin composite materials. RSC Adv. 2017, 7, 21252-21257. [CrossRef]

32. Tan, H.; Ramirez, C.M.; Miljkovic, N.; Li, H.; Rubin, J.P.; Marra, K.G.J.B. Thermosensitive injectable hyaluronic acid hydrogel for adipose tissue engineering. Biomaterials 2009, 30, 6844-6853. [CrossRef] [PubMed]

33. Pereira, L.; Amado, A.M.; Critchley, A.T.; Van de Velde, F.; Ribeiro-Claro, P.J. Identification of selected seaweed polysaccharides (phycocolloids) by vibrational spectroscopy (FTIR-ATR and FT-Raman). Food Hydrocoll. 2009, 23, 1903-1909. [CrossRef]

34. Khaliq, T.; Sohail, M.; Minhas, M.U.; Shah, S.A.; Jabeen, N.; Khan, S.; Rashid, H. Self-crosslinked chitosan/ k-carrageenan-based biomimetic membranes to combat diabetic burn wound infections. Int. J. Biol. Macromol. 2021, 197, 157-168. [CrossRef] [PubMed]

35. Shah, S.A.; Sohail, M.; Khan, S.A.; Kousar, M. Improved drug delivery and accelerated diabetic wound healing by chondroitin sulfate grafted alginate-based thermoreversible hydrogels. Mater. Sci. Eng. C 2021, 126, 112169. [CrossRef] [PubMed]

36. Shah, S.A.; Sohail, M.; Minhas, M.U.; Khan, S.; Hussain, Z.; Mahmood, A.; Abbasi, M. Curcumin-laden hyaluronic acid-coPullulan-based biomaterials as a potential platform to synergistically enhance the diabetic wound repair. International J. Biol. Macromol. 2021, 185, 350-368. [CrossRef]

37. Sun Han Chang, R.; Lee, J.C.-W.; Pedron, S.; Harley, B.A.; Rogers, S. A Rheological analysis of the gelation kinetics of an enzyme cross-linked PEG hydrogel. Biomacromolecules 2019, 20, 2198-2206. [CrossRef]

38. Gómez-Ordóñez, E. and P. Rupérez, FTIR-ATR spectroscopy as a tool for polysaccharide identification in edible brown and red seaweeds. Food Hydrocoll. 2011, 25, 1514-1520. [CrossRef]

39. Balqis, A.I.; Khaizura, M.N.; Russly, A.; Hanani, Z.N. Effects of plasticizers on the physicochemical properties of kappacarrageenan films extracted from Eucheuma cottonii. Int. J. Biol. Macromol. 2017, 103, 721-732. [CrossRef]

40. Kusumaningrum, I.K.; Wijaya, A.R.; Marfuah, S.; Fadilah, M. Optimation of Alkoxide formed step on Carboxymethyl Kappa Carrageenan synthesis. In Proceedings of the IOP Conference Series: Earth and Environmental Science, Bogor, Indonesia, 25 October 2018.

41. Al-Sibani, M.; Al-Harrasi, A.; Rhh, N. Characterization of Linear and Chemically Cross-linked Hyaluronic acid using Various Analytical Techniques Including FTIR, ESI-MS, H1 NMR, and SEM. J. Biochem. Anal. Stud. 2018, 3, 2576-5833. [CrossRef]

42. Lewandowska, K.; Sionkowska, A.; Grabska, S.; Kaczmarek, B.; Michalska, M. The miscibility of collagen/hyaluronic acid/chitosan blends investigated in dilute solutions and solids. J. Mol. Liq. 2016, 220, 726-730. [CrossRef]

43. Sabbagh, F.; Kiarostami, K.; Khatir, N.M.; Rezania, S.; Muhamad, I.I.; Hosseini, F. Effect of zinc content on structural, functional, morphological, and thermal properties of kappa-carrageenan/NaCMC nanocomposites. Polym. Test. 2021, 93, 106922. [CrossRef]

44. Branca, C.; Khouzami, K.; Wanderlingh, U.; D'Angelo, G. Effect of intercalated chitosan/clay nanostructures on concentrated pluronic F127 solution: A FTIR-ATR, DSC and rheological study. J. Colloid Interface Sci. 2018, 517, 221-229. [CrossRef]

45. Li, Z.; Huang, Y.; Peng, S.; Chen, X.; Zou, L.; Liu, W.; Liu, C. Liposomes consisting of pluronic F127 and phospholipid: Effect of matrix on morphology, stability and curcumin delivery. J. Dispers. Sci. Technol. 2019, 41, 207-213. [CrossRef]

46. Lewandowska, K.; Sionkowska, A.; Grabska, S.; Kaczmarek, B. Surface and thermal properties of collagen/hyaluronic acid blends containing chitosan. Int. J. Biol. Macromol. 2016, 92, 371-376. [CrossRef] [PubMed]

47. Lewandowska, K.; Alina, S.; Grabska, S.; Michalska, M. Characterisation of chitosan/hyaluronic acid blend films modified by collagen. Prog. Chem. Appl. Chitin Deriv. 2017, 22, 125-134. [CrossRef]

48. Layek, R.K.; Uddin, M.E.; Kim, N.H.; Lau, A.K.T.; Lee, J.H. Noncovalent functionalization of reduced graphene oxide with pluronic F127 and its nanocomposites with gum Arabic. Compos. Part B Eng. 2017, 128, 155-163. [CrossRef]

49. Yap, L.-S.; Yang, M.-C. Evaluation of hydrogel composing of Pluronic F127 and carboxymethyl hexanoyl chitosan as injectable scaffold for tissue engineering applications. Colloids Surf. B Biointerfaces 2016, 146, 204-211. [CrossRef] [PubMed] 
50. Nasir, N.; Ahmad, M.; Minhas, M.U.; Barkat, K.; Khalid, M.F. pH-responsive smart gels of block copolymer [pluronic F127-co-poly (acrylic acid)] for controlled delivery of Ivabradine hydrochloride: Its toxicological evaluation. J. Polym. Res. 2019, 26, 212. [CrossRef]

51. Jayaramudu, T.; Varaprasad, K.; Reddy, K.K.; Pyarasani, R.D.; Akbari-Fakhrabadi, A.; Amalraj, J. Chitosan-pluronic based Cu nanocomposite hydrogels for prototype antimicrobial applications. Int. J. Biol. Macromol. 2020, 143, 825-832. [CrossRef]

52. Chaturvedi, K.; Kulkarni, A.R.; Aminabhavi, T.M. Blend microspheres of poly (3-hydroxybutyrate) and cellulose acetate phthalate for colon delivery of 5-fluorouracil. Ind. Eng. Chem. Res. 2011, 50, 10414-10423. [CrossRef]

53. Wahid, F.; Zhou, Y.-N.; Wang, H.-S.; Wan, T.; Zhong, C.; Chu, L.-Q. Injectable self-healing carboxymethyl chitosan-zinc supramolecular hydrogels and their antibacterial activity. Int. J. Biol. Macromol. 2018, 114, 1233-1239. [CrossRef]

54. Ojha, J.; Nanda, R.; Dorai, K. NMR investigation of the thermogelling properties, anomalous diffusion, and structural changes in a Pluronic F127 triblock copolymer in the presence of gold nanoparticles. Colloid Polym. Sci. 2020, 298, 1-15. [CrossRef]

55. Picheth, G.F.; Da Silva, L.C.; Giglio, L.P.; Plivelic, T.S.; de Oliveira, M.G. S-nitrosothiol-terminated Pluronic F127: Influence of microstructure on nitric oxide release. J. Colloid Interface Sci. 2020, 576, 457-467. [CrossRef] [PubMed]

56. Jin, E.; Zhang, Z.; Lian, H.; Chen, X.; Xiao, C.; Zhuang, X.; Chen, X. Injectable electroactive hydrogels based on Pluronic ${ }^{\circledR}$ F127 and tetraaniline copolymer. Eur. Polym. J. 2017, 88, 67-74. [CrossRef]

57. Wende, F.J.; Xue, Y.; Nestor, G.; Öhrlund, Å.; Sandström, C. Relaxation and diffusion of water protons in BDDE cross-linked hyaluronic acid hydrogels investigated by NMR spectroscopy-Comparison with physicochemical properties. Carbohydr. Polym. 2020, 248, 116768. [CrossRef] [PubMed]

58. Hu, B.; Du, L.; Matsukawa, S. NMR study on the network structure of a mixed gel of kappa and iota carrageenans. Carbohydr. Polym. 2016, 150, 57-64. [CrossRef]

59. Yang, D.; Yang, H. The temperature dependent extraction of polysaccharides from eucheuma and the rheological synergistic effect in their mixtures with kappa carrageenan. LWT 2020, 129, 109515. [CrossRef]

60. Chirumamilla, S.K.; Padasala, U.D.; Aravally, H.; Vuppalapati, L.; Cherukuri, S. Solubility and Dissolution Enhancement of Meropenem by Nano Suspension Approach. J. Young Pharm. 2017, 9, 429-435. [CrossRef]

61. Mangal, S.; Park, H.; Zeng, L.; Heidi, H.Y.; Lin, Y.-W.; Velkov, T.; Zhou, Q.T. Composite particle formulations of colistin and meropenem with improved in-vitro bacterial killing and aerosolization for inhalation. Int. J. Pharm. 2018, 548, 443-453. [CrossRef] [PubMed]

62. Liew, J.W.Y.; Loh, K.S.; Ahmad, A.; Lim, K.L.; Wan Daud, W.R. Synthesis and characterization of modified k-carrageenan for enhanced proton conductivity as polymer electrolyte membrane. PLoS ONE 2017, 12, e0185313. [CrossRef]

63. Du, L.; Brenner, T.; Xie, J.; Matsukawa, S. A study on phase separation behavior in kappa/iota carrageenan mixtures by micro DSC, rheological measurements and simulating water and cations migration between phases. Food Hydrocoll. 2016, 55, 81-88. [CrossRef]

64. Schieber, J.; Lazar, R.; Bohacs, K.; Klimentidis, R.; Dumitrescu, M.; Ottmann, J. An SEM study of porosity in the Eagle Ford Shale of Texas-Pore types and porosity distribution in a depositional and sequence-stratigraphic context. In The Eagle Ford Shale: $A$ Renaissance in U.S. Oil Production; American Association of Petroleum Geologists: Tulsa, OK, USA, 2016; pp. 167-186.

65. Klaver, J.; Desbois, G.; Littke, R.; Urai, J.L. BIB-SEM pore characterization of mature and post mature Posidonia Shale samples from the Hils area, Germany. Int. J. Coal Geol. 2016, 158, 78-89. [CrossRef]

66. Yang, M.; Wang, L.; Xia, Y. Ammonium persulphate induced synthesis of polymethyl methacrylate grafted sodium alginate composite films with high strength for food packaging. Int. J. Biol. Macromol. 2019, 124, 1238-1245. [CrossRef]

67. Chen, C.-H.; Chen, S.-H.; Mao, S.-H.; Tsai, M.-J.; Chou, P.-Y.; Liao, C.-H.; Chen, J.-P. Injectable thermosensitive hydrogel containing hyaluronic acid and chitosan as a barrier for prevention of postoperative peritoneal adhesion. Carbohydr. Polym. 2017, 173, 721-731. [CrossRef] [PubMed]

68. Sakai, S.; Ohi, H.; Taya, M. Gelatin/Hyaluronic Acid Content in Hydrogels Obtained through Blue Light-Induced Gelation Affects Hydrogel Properties and Adipose Stem Cell Behaviors. Biomolecules 2019, 9, 342. [CrossRef] [PubMed]

69. Tytgat, L.; Vagenende, M.; Declercq, H.; Martins, J.; Thienpont, H.; Ottevaere, H.; Van Vlierberghe, S. Synergistic effect of K-carrageenan and gelatin blends towards adipose tissue engineering. Carbohydr. Polym. 2018, 189, 1-9. [CrossRef]

70. Cidade, M.; Ramos, D.; Santos, J.; Carrelo, H.; Calero, N.; Borges, J. Injectable Hydrogels Based on Pluronic/Water Systems Filled with Alginate Microparticles for Biomedical Applications. Materials 2019, 12, 1083. [CrossRef] [PubMed]

71. Quah, S.P.; Smith, A.J.; Preston, A.N.; Laughlin, S.T.; Bhatia, S.R. Large-area alginate/PEO-PPO-PEO hydrogels with thermoreversible rheology at physiological temperatures. Polymer 2018, 135, 171-177. [CrossRef]

72. Demeter, M.; Virgolici, M.; Vancea, C.; Scarisoreanu, A.; Kaya, M.G.A.; Meltzer, V. Network structure studies on $\gamma$-irradiated collagen-PVP superabsorbent hydrogels. Radiat. Phys. Chem. 2017, 131, 51-59. [CrossRef]

73. Makvandi, P.; Ali, G.W.; Della Sala, F.; Abdel-Fattah, W.I.; Borzacchiello, A. Hyaluronic acid/corn silk extract based injectable nanocomposite: A biomimetic antibacterial scaffold for bone tissue regeneration. Mater. Sci. Eng. C 2020, 107, 110195. [CrossRef]

74. Yokota, S.; Tagawa, S.; Kondo, T. Facile surface modification of amphiphilic cellulose nanofibrils prepared by aqueous counter collision. Carbohydr. Polym. 2020, 255, 117342. [CrossRef] [PubMed]

75. Dehghan-Baniani, D.; Chen, Y.; Wang, D.; Bagheri, R.; Solouk, A.; Wu, H. Injectable in situ forming kartogenin-loaded chitosan hydrogel with tunable rheological properties for cartilage tissue engineering. Colloids Surf. B Biointerfaces 2020, $192,111059$. [CrossRef] [PubMed] 
76. Jin, R.; Teixeira, L.M.; Dijkstra, P.J.; Karperien, M.; Van Blitterswijk, C.; Zhong, Z.; Feijen, J. Injectable chitosan-based hydrogels for cartilage tissue engineering. Biomaterials 2009, 30, 2544-2551. [CrossRef] [PubMed]

77. Jin, R.; Teixeira, L.M.; Krouwels, A.; Dijkstra, P.J.; Van Blitterswijk, C.; Karperien, M.; Feijen, J. Synthesis and characterization of hyaluronic acid-poly (ethylene glycol) hydrogels via Michael addition: An injectable biomaterial for cartilage repair. Acta Biomater. 2010, 6, 1968-1977. [CrossRef] [PubMed]

78. Wang, B.; Wu, X.; Li, J.; Hao, X.; Lin, J.; Cheng, D.; Lu, Y.J.P. Thermosensitive behavior and antibacterial activity of cotton fabric modified with a chitosan-poly (N-isopropylacrylamide) interpenetrating polymer network hydrogel. Polymers 2016, 8, 110. [CrossRef]

79. Kim, W.K.; Choi, J.H.; Shin, M.E.; Kim, J.W.; Kim, P.Y.; Kim, N.; Khang, G. Evaluation of cartilage regeneration of chondrocyte encapsulated gellan gum-based hyaluronic acid blended hydrogel. Int. J. Biol. Macromol. 2019, 141, 51-59. [CrossRef]

80. Tavakoli, S.; Kharaziha, M.; Kermanpur, A.; Mokhtari, H. Sprayable and injectable visible-light Kappa-carrageenan hydrogel for in-situ soft tissue engineering. Int. J. Biol. Macromol. 2019, 138, 590-601. [CrossRef]

81. Zhang, H.; Ren, P.; Jin, Y.; Ren, F. Injectable, strongly compressible hyaluronic acid hydrogels via incorporation of Pluronic F127 diacrylate nanomicelles. Mater. Lett. 2019, 243, 112-115. [CrossRef]

82. Chen, M.; Li, C.; Nie, F.; Liu, X.; Pipinos, I.I.; Li, X. Synthesis and characterization of a hyaluronic acid-based hydrogel with antioxidative and thermosensitive properties. RSC Adv. 2020, 10, 33851-33860. [CrossRef]

83. Nascimento, M.; Franco, M.; Yokaichyia, F.; de Paula, E.; Lombello, C.; de Araujo, D. Hyaluronic acid in Pluronic F-127/F-108 hydrogels for postoperative pain in arthroplasties: Influence on physico-chemical properties and structural requirements for sustained drug-release. Int. J. Biol. Macromol. 2018, 111, 1245-1254. [CrossRef]

84. Azizi, S.; Mohamad, R.; Rahim, R.A.; Mohammadinejad, R.; Ariff, A.B. Hydrogel beads bio-nanocomposite based on KappaCarrageenan and green synthesized silver nanoparticles for biomedical applications. Int. J. Biol. Macromol. 2017, 104, 423-431. [CrossRef]

85. Selvakumaran, S.; Muhamad, I.I.; Abd Razak, S.I. Evaluation of kappa carrageenan as potential carrier for floating drug delivery system: Effect of pore forming agents. Carbohydr. Polym. 2016, 135, 207-214. [CrossRef]

86. Meshkini, A.; Oveisi, H. Methotrexate-F127 conjugated mesoporous zinc hydroxyapatite as an efficient drug delivery system for overcoming chemotherapy resistance in osteosarcoma cells. Colloids Surf. B Biointerfaces 2017, 158, 319-330. [CrossRef] [PubMed]

87. Mdlovu, N.V.; Mavuso, F.A.; Lin, K.-S.; Chang, T.-W.; Chen, Y.; Wang, S.S.-S.; Lin, Y.-S. Iron oxide-pluronic F127 polymer nanocomposites as carriers for a doxorubicin drug delivery system. Colloids Surf. A Physicochem. Eng. Asp. 2019, 562, 361-369. [CrossRef]

88. Higuchi, T. Mechanism of sustained-action medication. Theoretical analysis of rate of release of solid drugs dispersed in solid matrices. J. Pharm. Sci. 1963, 52, 1145-1149. [CrossRef] [PubMed] 